\title{
On the supposed occurrence of phosophoric acid in rocks of igneous origin
}

\section{Prof. C. Kersten}

To cite this article: Prof. C. Kersten (1845) On the supposed occurrence of phosophoric acid in rocks of igneous origin, Philosophical Magazine Series 3, 27:178, 155-156, DOI: 10.1080/14786444508645243

To link to this article: http://dx.doi.org/10.1080/14786444508645243

册 Published online: 30 Apr 2009.

Submit your article to this journal $\lceil\pi$

Џ Article views: 3

Q View related articles $₫$ 
second magnitude when they resemble fixed stars of the first magnitude; and thus with the rest. Among 5302 meteors, the author counted eight shooting globes and eighty shooting stars of the first magnitude; whence it follows that, if no obstacle prevented, an observer would see one shooting globe a week, and one falling star of the first magnitude each night of eleven hours.

In general the falling stars have the same tint as the fixed stars. Sometimes this colour passes into yellow, then into a bluish or a greenish tint, in proportion as the meteor approaches the horizon.

Among all these meteors there are some red ones, which travel slowly, and have a globular form, like a billiard-ball coloured red. The author thinks that these are of a particular character. Lastly, he distinguishes others which are extinguished at their highest point of brilliancy, as if they were plunged into water.

With respect to the trains which some stars leave behind them, these cannot be compared to smoke, but rather to a shower of sparks like that of rockets. The train begins and ends always with the star producing it, but it continues one or two seconds after the disappearance of that star. Sometimes the star breaks up into fragments, which form a continuation of the train, and which vanish almost as soon. No star has ever caused any audible noise, whether remaining simple, or producing a train, or separating into fragments.

In general the course of shooting stars is rectilinear, or rather in an arc of a large circle. The author has seen fifteen whose course was curvilinear.

At the conclusion of his investigation the author has given a catalogue of the most remarkable shooting stars, with the indication of the characters which they have presented. Before proceeding to the theoretical part of the subject he announces some historical researches relative to it.-Comptes Rendus, May 5th and June 2nd, 1845.

\section{ON THE SUPPOSED OCCURRENCE OF PHOSPHORIC ACID IN ROCKS OF IGNEOUS ORIGIN. BY PROF. C. KERSTEN.}

In the 'Philosophical Magazine,' vol. xxiv. p. 467, is an abstract of a paper by Dr. Fownes, on the occurrence of phosphoric acid in rocks of igneous origin. Dr. Fownes asserts that he found small quantities of phosphoric acid in combination with alumina, \&c. in all these rocks, and supposes that it is probably to this presence of phosphoric acid that many soils which have originated by the decomposition of those rocks owe their fertility. He found phosphoric acid in a porcelain clay from Dartmoor, in the gray vesicular lava from the Rhine, and in the white trachyte from the Drachenfels on the Rhine, in tolerable quantity in the two latter rocks; further, in several basalts, in porphyritic lava inclosing crystals of hornblende from Vesuvius, and in volcanic tufa from the same locality in considerable quantity. As these observations of Dr. Fownes appeared of some importance in a geognostical and agricultural point of view, and, as far as I am aware, no phosphoric acid had hitherto been de. tected in the above-mentioned rocks, I was induced to repeat $\mathrm{Dr}$. Fownes's experiments. 
The following rocks were examined for phosphoric acid:-1st, porcelain earth from Aue in Saxony; 2nd, porcelain earth from Bayonne; 3rd, gray vesicular lava from Niedermennig on the Rhine ; 4th, white trachyte from the Drachenfels; 5 th, basalt from the Meissner in Hessia ; 6th. Trass from Vesuvius.

The following was the mode of examination:-The finely-pulverized rocks were fused with 4 times the quantity of chemicallypure soda, the fused masses digested in water, and the liquids filtered from the insoluble residues neutralized with nitric acid. These neutralized liquids were now evaporated to dryness, and after treatment with water and separation of the silicic acid, tested with nitrate of silver and the other known reagents for phosphoric acid.

In all the above rocks, however, not the least trace of phosphoric acid could be detected; consequently the above-mentioned observations of Dr. Fownes are founded on some error*. In the gray vesicular lava from Niedermennig there was found a quantity of chlorine; and on boiling it in the pulverized state with water and eva. porating the liquid, small quantities of chloride of sodium were obtained ; at the sume time with this a brown organic substance was extracted, which coloured the water brownish on evaporation and was carbonified on ignition.-Journ. für Prakt. Chem., March 31, 1845.

EXAMINATION OF SOME NATIVE AND ARTIFICIAL COMPOUNDS OF PHOSPHORIC ACID. BY C. RAMMELSBERG.

Wagnerite (Pleuroklase).

We are indebted for the only analysis of this exceedingly rare mineral to Fuchs, who obtained in the year 1821 the following results : phosphoric acid $41 \cdot 73$ per cent, magnesia $466^{\circ} 66$, peroxide of iron $5^{\circ} 0$, peroxide of manganese $0 \cdot 5$, hydrofluoric acid $6 \cdot 5$. Fuchs decomposed the mineral with sulphuric acid, and separated the sulphate from the phosphate of magnesia by water. The phosphate of magnesia was decomposed by boiling it with a solution of potash. The phosphoric acid and fluorine were not directly estimated. If his method of analysis be minutely examined, the results are seen to be only approximative, and a repetition of the analysis would be very desirable. In the specimens selected by the author for analysis, there were large, opake, reddish, and small transparent, wine-yellow crystals of wagnerite, imbedded in a green aluminous mass and accompanied with quartz, calcareous spar and bitter spar. Its specific gravity, according to Fuchs, is $3 \cdot 13$. The author found it 3.068 at a temperature of $57^{\circ} \mathrm{F}$. in the transparent parts, and 2.985 in the opake portions.

Three analyses were made by methods differing as widely as possible.

1. The substance reduced to a fine powder was treated with sulphuric acid in a platinum crucible. This, even in the cold, caused the evolution of fumes of fluoride of silicium from the admixture of

* The observations of Dr. Fownes have, however, been fully confirmed by W. Sullivan, Esq., as will appear from a communication to be inserted in our next.-ED. PHIL. MAG. 